\title{
Second-Generation Antipsychotics and Neuroleptic Malignant Syndrome: Systematic Review and Case Report Analysis
}

\author{
Martino Belvederi Murri • Argentina Guaglianone • Michele Bugliani • \\ Pietro Calcagno • Matteo Respino · Gianluca Serafini • \\ Marco Innamorati $\cdot$ Maurizio Pompili $\cdot$ Mario Amore
}

Published online: 13 January 2015

(C) The Author(s) 2015. This article is published with open access at Springerlink.com

\begin{abstract}
Background Neuroleptic malignant syndrome (NMS) is a rare, severe, idiosyncratic adverse reaction to antipsychotics. Second-generation antipsychotics (SGAs) were originally assumed to be free from the risk of causing NMS, however several cases of NMS induced by SGAs (SGANMS) have been reported.

Objectives The aim of this study was to systematically review available studies and case reports on SGA-NMS
\end{abstract}

Electronic supplementary material The online version of this article (doi:10.1007/s40268-014-0078-0) contains supplementary material, which is available to authorized users.

M. Belvederi Murri ( $₫)$ · A. Guaglianone · M. Bugliani ·

P. Calcagno · M. Respino - G. Serafini - M. Amore

Section of Psychiatry, Department of Neuroscience,

Rehabilitation, Ophthalmology, Genetics, Maternal and Child

Health, University of Genoa, Largo Rosanna Benzi, 10,

16132 Genoa, Italy

e-mail: martino.belvederi@gmail.com

M. Belvederi Murri

Department of Psychological Medicine, Institute of Psychiatry,

King's College London, London, UK

M. Innamorati · M. Pompili

Department of Neurosciences, Mental Health and Sensory

Organs, Suicide Prevention Center, Sant'Andrea Hospital,

Sapienza University of Rome, Rome, Italy and compare the presentation of NMS induced by different SGAs.

Data Sources Citations were retrieved from PubMed up to November 2013, and from reference lists of relevant citations.

Study Eligibility Criteria Eligibility criteria included (a) primary studies reporting data on NMS, with at least $50 \%$ of the sample receiving SGAs; or (b) case reports and case reviews reporting on NMS induced by SGA monotherapy, excluding those due to antipsychotic withdrawal.

Study Appraisal and Synthesis Methods A standardized method for data extraction and coding was developed for the analysis of eligible case reports.

Results Six primary studies and 186 individual cases of NMS induced by SGAs were included. Primary studies suggest that SGA-NMS is characterized by lower incidence, lower clinical severity, and less frequent lethal outcome than NMS induced by first-generation antipsychotics. Systematic analysis of case reports suggests that even the most recently marketed antipsychotics are not free from the risk of inducing NMS. Furthermore, clozapine-, aripiprazole- and amisulpride-induced NMS can present with atypical features more frequently than other SGA-NMS, i.e. displaying less intense extrapyramidal symptoms or high fever.

Limitations Case reports report non-systematic data, therefore analyses may be subject to bias.

Conclusions and Implications of Key Findings Clinicians should be aware that NMS is virtually associated with all antipsychotics, including those most recently marketed. Although apparently less severe than NMS induced by older antipsychotics, SGA-NMS still represent a relevant clinical issue. 


\section{Key Points}

Neuroleptic malignant syndrome (NMS) induced by second-generation antipsychotics is characterized by lower incidence, lower clinical severity, and less frequent lethal outcome than NMS induced by firstgeneration antipsychotics.

Even the most recently marketed antipsychotics are not free from the risk of inducing NMS.

Clozapine-, aripiprazole- and amisulpride-induced NMS can present with atypical features more frequently than other SGA-NMS, i.e. displaying less intense extrapyramidal symptoms or high fever.

\section{Introduction}

Neuroleptic malignant syndrome (NMS) is a rare, unpredictable adverse reaction associated with antipsychotic use. It is generally characterized by rigidity, tremor, fever, dysregulated sympathetic nervous system hyperactivity, alterations of mental status, leukocytosis, and creatine kinase (CK) elevation [1]. If not promptly recognized and treated, NMS can lead to patient death or permanent damages, such as neurological sequelae [2, 3]. Secondgeneration antipsychotics (SGAs) were initially assumed to be free from the risk of inducing NMS because of their more favorable pharmacodynamic profile [4]; however, after they had been marketed, cases of NMS induced by SGAs (SGA-NMS) began to be reported, with the first case implicating clozapine [5]. Notably, several cases of NMS induced by clozapine (CLZ-NMS) presented with different clinical features than those of NMS induced by first-generation antipsychotics (FGA-NMS), i.e. lacking cardinal signs or symptoms. These observations led to the hypothesis that 'atypical' antipsychotics might determine 'atypical' forms of NMS on the basis of different pharmacological properties [6]. Furthermore, newer SGAs such as aripiprazole [7] and amisulpride [8] possess peculiar pharmacodynamic profiles $[9,10]$ which might be associated with different NMS presentation. At present, while it is commonly accepted that no antipsychotic is free from the risk of inducing NMS, there is still uncertainty on the clinical profile of SGA-NMS $[6,11]$.

SGAs are the most commonly prescribed antipsychotics [12] but our knowledge on SGA-NMS continues to be very limited given the intrinsic difficulties of studying NMS under experimental conditions. Of note, case reports remain one of the main sources of information for clinicians. Hence, there is still great uncertainty regarding SGA-NMS epidemiology [13, 14], diagnostic definition [1], presentation, clinical course, and pathophysiology [15], and possible influence of concomitant drugs [16]. Considerable time has elapsed since this topic was examined in a systematic fashion [6], hence our aim was to review the available evidence on SGA-NMS, considering both primary studies and case reports. In order to minimize the risk of bias in the interpretation of available evidence, a standardized approach was used to analyze the available information.

\section{Methods}

\subsection{Search Strategy}

The Pubmed database was searched using the following search string: <Malignant AND ('Antipsychotic Agents' [Mesh] OR amisulpride OR aripiprazole OR asenapine OR clozapine OR olanzapine OR paliperidone OR quetiapine OR risperidone OR ziprasidone OR iloperidone OR zotepine OR sertindole OR lurasidone) $>$. Two independent researchers screened and systematically assessed all retrieved references to identify (1) primary studies on SGA-NMS, i.e. those conducted on clinical samples; and (3) case reports or case reviews of SGA-NMS. All works published prior to November 2013 as well as relevant citations obtained from bibliographies were screened. In addition to citations in English, those written in Italian, Spanish, and French were included as two researchers were fluent in these languages.

\subsection{Inclusion and Exclusion Criteria}

For the review of primary studies, any study that reported data on NMS developed during a treatment course with any SGA was included. If studies were conducted on samples where NMS was developed during treatment with both FGAs and SGAs, only those where at least $50 \%$ of participants were treated with SGAs were included.

For the review of case reports, the aim was to obtain the maximum degree of clinical homogeneity; hence, cases (a) with an unclear diagnosis of NMS, meaning that the reporting clinician did not explicitly state this diagnosis, irrespective of the set of diagnostic criteria that were used [1]; (b) where an SGA was given in association with another antipsychotic (either FGA or SGA) in the week preceding the diagnosis of NMS; and (c) where the NMS was apparently induced by withdrawal of an antipsychotic $[15,17]$, were excluded. 


\subsection{Data Extraction}

For the case review, researchers extracted, coded, and analyzed relevant data available from case reports using a standardized method (described in detail in the Methods section of the Online Resource). Briefly, two researchers (AG and MB), blinded to each other, coded for each case detailed information on subject sociodemographic and clinical features, treatment with SGAs and other psychotropic drugs, NMS clinical presentation, course and management. In order to provide a description of the time course of NMS, all available data relative to the temporal sequence of events were extracted. An adapted version of the Francis-Yacoub NMS Rating Scale [18] was used to improve the homogeneity for the ratings of NMS severity.

\subsection{Statistical Analysis}

For all cases of SGA-NMS, a summary of descriptive data was reported, including demographic and clinical characteristics. Furthermore, to explore the presence of potential intraclass differences between cases of NMS prompted by different SGAs, exploratory statistical analyses were conducted comparing the demographic and clinical characteristics of cases by means of the Chi-square test and analysis of variance (ANOVA). Since description of the case reports was not conducted in a systematic fashion, a significant amount of missing data was expected; to provide the reader with an estimation of the representativity of results, the percentage of cases with missing data for each comparison is reported. Also, Pearson's correlation index (R) and Student's $t$ test were used to test whether sociodemographic and clinical features of NMS showed associations with the global severity of NMS (expressed as the total severity score for each case). Statistical analyses were conducted including only the SGANMS groups where a sufficient number of NMS cases were available (setting an arbitrary threshold of ten cases per subgroup), using the Statistical Package for Social Sciences, version 15.0 (SPSS Inc., Chicago, IL, USA).

\section{Results}

\subsection{Search Results}

The search yielded 918 citations (see Fig. S1 in the Online Resource). Of these, six primary studies were included in the review [11, 14, 19-22], while 247 case reports were potentially eligible for inclusion. After full-text review, 105 more citations were excluded, leading to the inclusion of 142 citations (case reports or case series). These accounted for 186 individual case reports of SGA-NMS. References for included case reports are included in the
References section of the Online Resource. Table 1 reports the description of the included primary studies.

\subsection{Case Report Analysis}

Tables 2, 3 and 4 report data on cases of SGA-NMS that were considered for statistical analysis $(n=155)$ : 42 cases of NMS were induced by olanzapine (OLA, mean dose $12 \pm 5.8 \mathrm{mg}$ ), 44 by risperidone (RSP, mean dose $3.7 \pm 3.2 \mathrm{mg}$ ), 19 by quetiapine (QUE, $335 \pm 270 \mathrm{mg}$ ), 36 by clozapine (CLZ, $332 \pm 263 \mathrm{mg}$ ), and 14 by aripiprazole (ARP, $18.9 \pm 9.2 \mathrm{mg}$ ). Table 5 reports descriptive data of those cases of SGA-NMS for which only descriptive analyses are provided. These were induced by amisulpride (AMI, $n=7$; mean dose $480 \pm 179 \mathrm{mg}$ ), ziprasidone (ZPR, $n=6 ; 86.7 \pm 46.8 \mathrm{mg}$ ), paliperidone (PAL, $n=4 ; 7.5 \pm 1.7 \mathrm{mg}$ ), and zotepine (ZOT, $n=4$; $325 \pm 247 \mathrm{mg}$ ). Lastly, because of a low number of cases, ten cases of NMS induced by other antipsychotics (perospirone, clotiapine, tiapride, iloperidone, asenapine, remoxipride) were excluded from the review.

The majority of case reports did not specify which diagnostic criteria set was used for the diagnosis of NMS ( $n=131,70.1 \%$ ), whereas in the remainder of cases the Diagnostic and Statistical Manual of Mental Disorders, 4th edition, text revision (DSM-IV-TR) criteria were used most commonly ( $n=35,18.7 \%$ ) [23], followed by the criteria of Levenson $(n=13,7 \%)$ [24], Sachdev $(n=3,1.6 \%)$ [25], Pope et al. $(n=2,1.1 \%)$ [26], and Caroff and Mann $(n=2,1.1 \%)$ [27].

\subsection{Intraclass Comparison of Cases of Second- Generation Antipsychotic-Induced Neuroleptic Malignant Syndrome (SGA-NMS)}

\subsubsection{Sociodemographic, Clinical Features and Treatment with SGAs}

Table 1 reports the comparison of subjects' sociodemographic and clinical features by each SGA-NMS. In the overall sample, the mean age was $41.5 \pm 20.2$. The majority were males $(62.6 \%)$, and the diagnoses were psychotic disorders (58.3\%), mood disorders $(23.2 \%)$, dementia $(9.3 \%)$, or other disorders $(9.3 \%)$. Half of the subjects receiving CLZ $(50 \%)$ and one-third of those treated with olanzapine $(34.8 \%)$ had already suffered from NMS in the past, whereas none of the subjects in the aripiprazole group ( $p=0.04$ ) had developed NMS.

Among those patients receiving risperidone and aripiprazole, more were antipsychotic-naïve than in the clozapine subgroup (41.2 and 38.5 vs. $4.0 \% ; p=0.01$ ). The mean reported doses of SGAs on the day of NMS insurgence were very similar between the five subgroups $(p=0.89)$. 


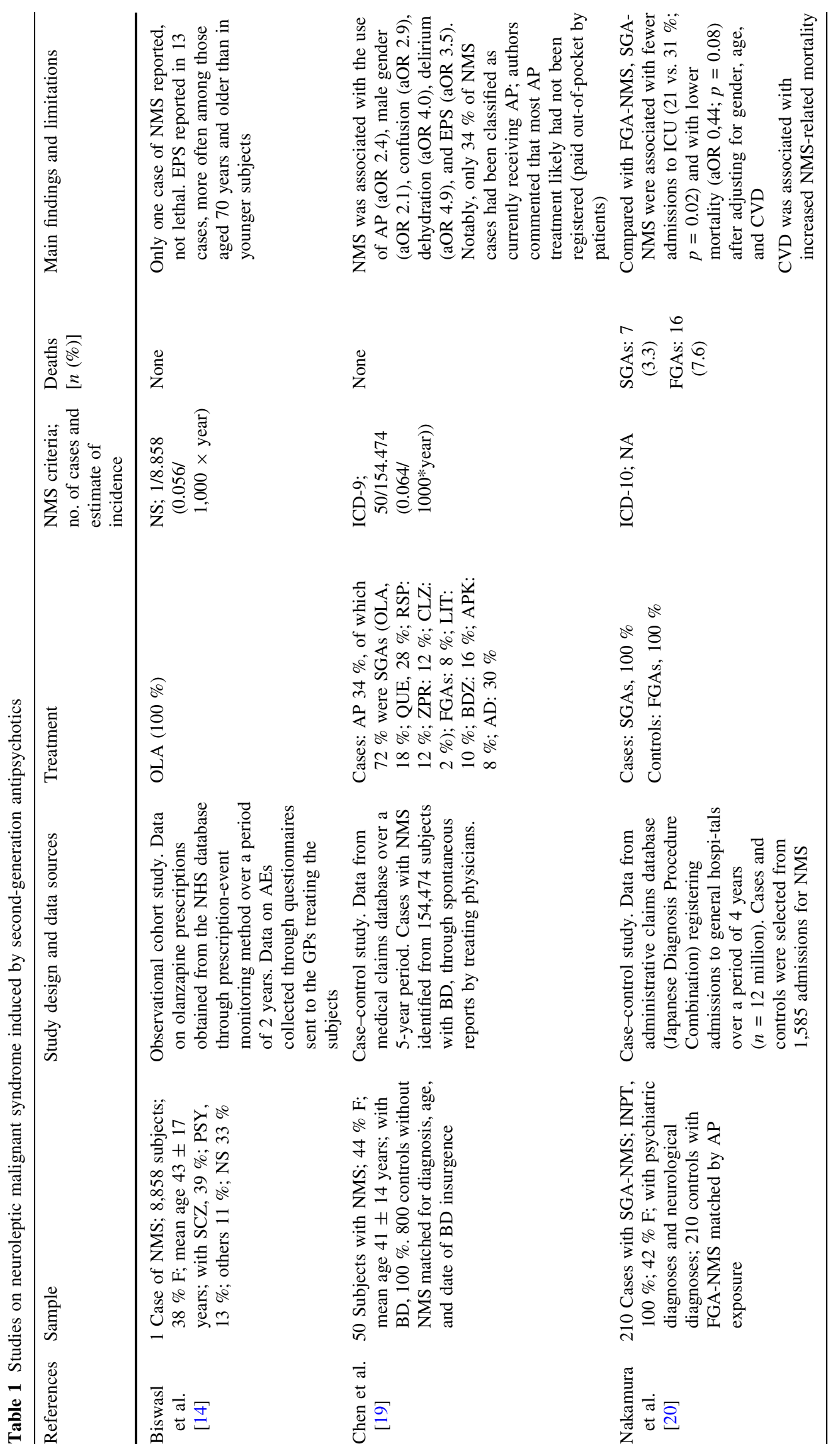




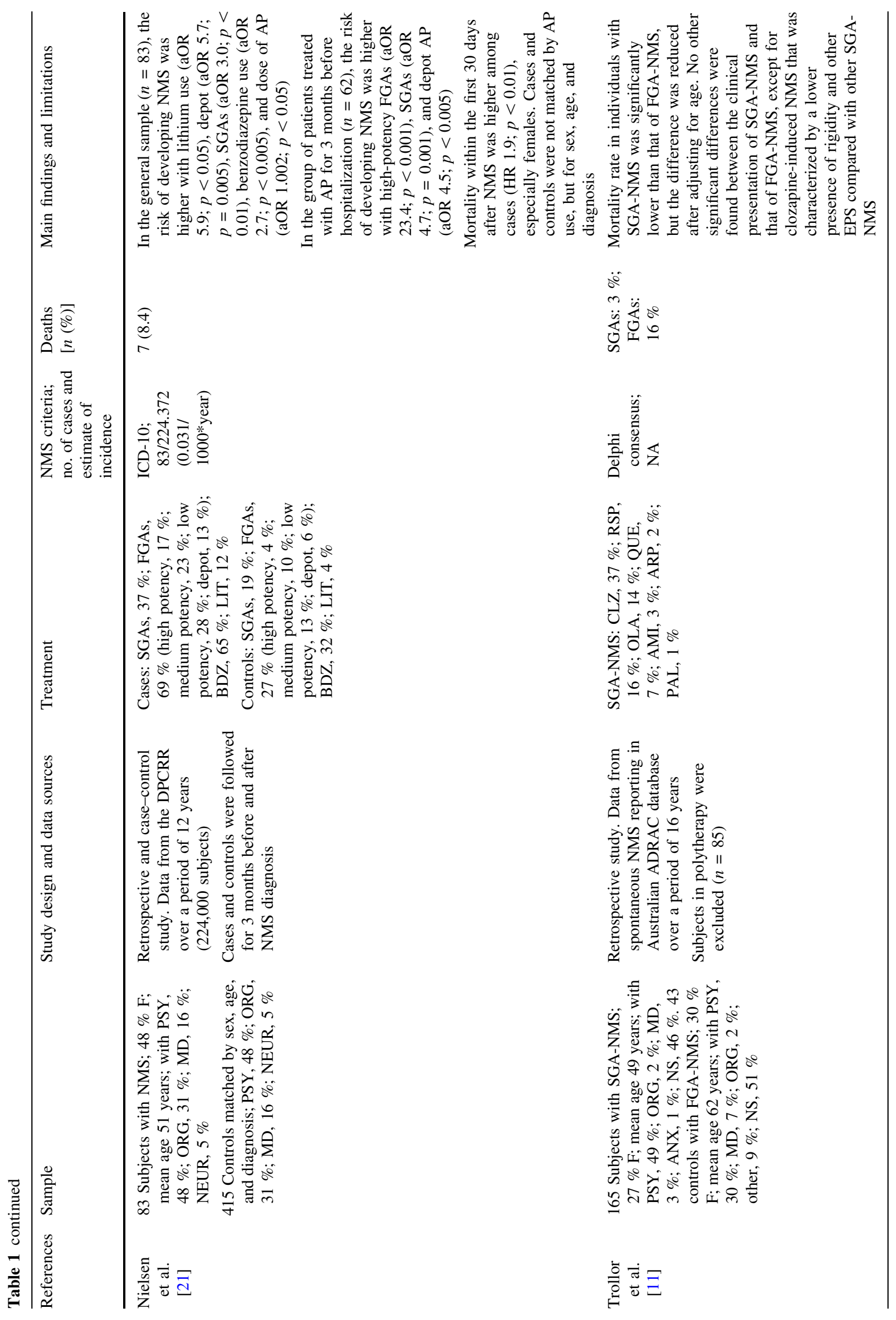




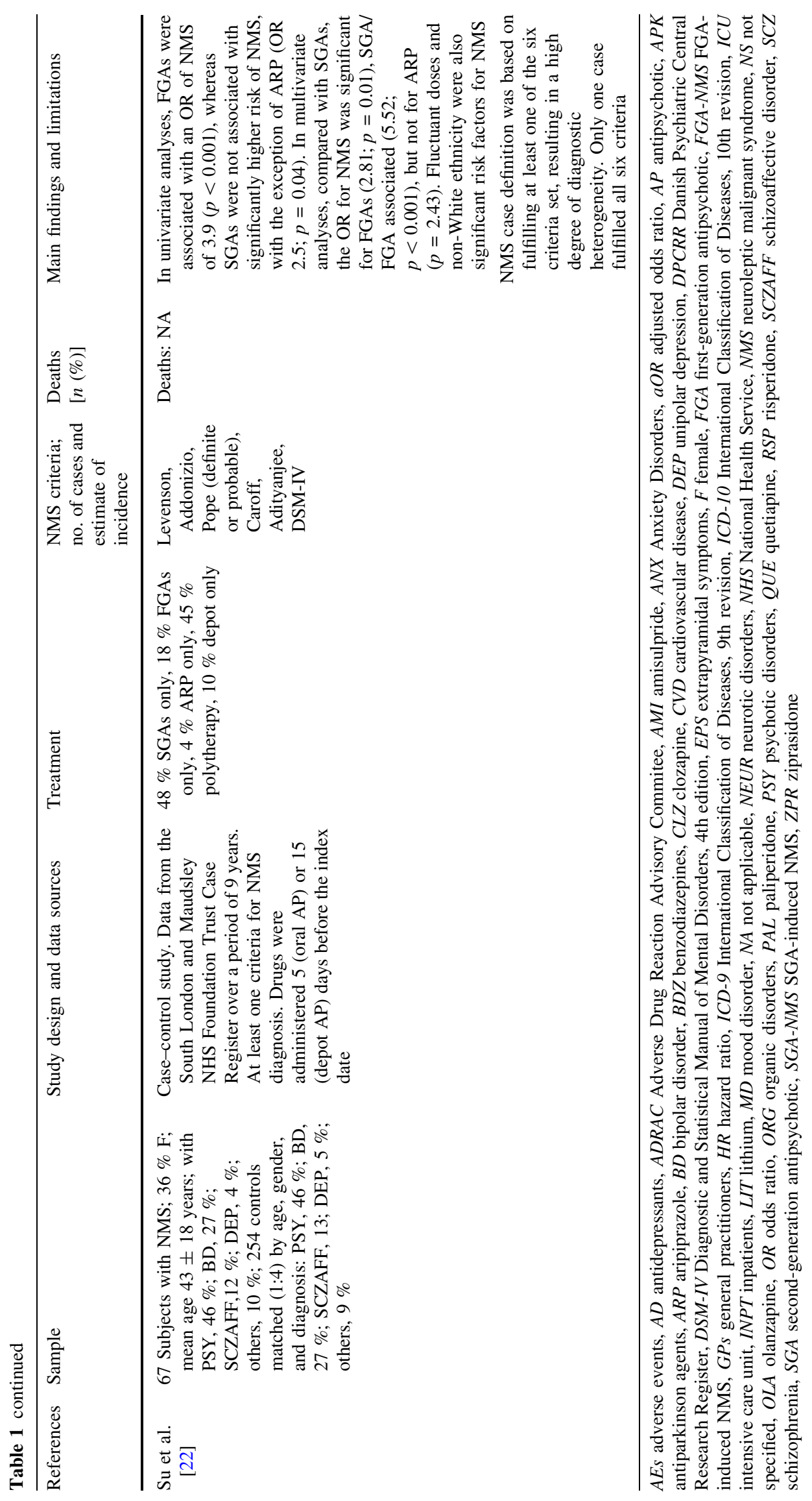


Table 2 Cases of neuroleptic malignant syndrome induced by olanzapine, quetiapine, risperidone, aripiprazole, and clozapine

\begin{tabular}{|c|c|c|c|c|c|c|c|}
\hline & $\begin{array}{l}\text { OLA } \\
(n=42)\end{array}$ & $\begin{array}{l}\text { QUE } \\
(n=19)\end{array}$ & $\begin{array}{l}\text { RSP } \\
(n=44)\end{array}$ & $\begin{array}{l}\text { ARP } \\
(n=14)\end{array}$ & $\begin{array}{l}\text { CLZ } \\
(n=36)\end{array}$ & $\begin{array}{l}\text { Missing } \\
{[n(\%)]}\end{array}$ & Statistics \\
\hline Gender [female; \%] & 33.3 & 42.1 & 50 & 42.9 & 22.2 & - & $\chi^{2}=7.18, d f=4, p=0.13$ \\
\hline Age [years; mean $\pm \mathrm{SD}$ ] & $46.2 \pm 22.4$ & $45.3 \pm 18.8$ & $39.6 \pm 21.2$ & $32.1 \pm 18.2$ & $39.9 \pm 16.3$ & - & $F=1.68, d f=4, p=0.16$ \\
\hline Ethnicity [Caucasian; \%] & 41.2 & 42.9 & 55 & 60 & 87.5 & $93(60)$ & $\chi^{2}=9.74, d f=12, p=0.64^{\mathrm{c}}$ \\
\hline Diagnosis [\%] & & & & & & $4(2.6)$ & $\chi^{2}=13.99, d f=12, p=0.3$ \\
\hline Psychotic disorders & 52.5 & 44.4 & 50 & 71.4 & 77.1 & & \\
\hline Mood disorders & 25 & 27.8 & 25 & 21.4 & 17.1 & & \\
\hline Dementia & 15 & 15 & 9.1 & - & 2.9 & & \\
\hline Other & 7.5 & 7.5 & 15.9 & 7.1 & 2.9 & & \\
\hline Previous NMS [\%] & 34.8 & 12.5 & 12.5 & 0 & 50 & $119(76)$ & $\chi^{2}=9.74, d f=4, p=0.04^{* \mathrm{c}}$ \\
\hline AP naive [\%] & 26.7 & 15.4 & 41.2 & 38.5 & 4.0 & $40(26)$ & $\chi^{2}=12.15, d f=4, p=0.02^{*, \mathrm{c}}$ \\
\hline Dose $[\mathrm{mg} ;$ mean $\pm \mathrm{SD}]$ & $12.1 \pm 5.9$ & $335 \pm 270$ & $3.7 \pm 3.2$ & $18.9 \pm 9.2$ & $332 \pm 263$ & $23(15)$ & - \\
\hline $\mathrm{CPZ}$ eq $[$ mean $\pm \mathrm{SD}]$ & $253 \pm 124$ & $236 \pm 190$ & $279 \pm 240$ & $295 \pm 144$ & $308 \pm 243$ & $23(15)$ & $F=0.48, d f=4, p=0.75$ \\
\hline Dose increase $[\%]^{\mathrm{a}}$ & 33.3 & 15.8 & 25 & 50 & 36.1 & - & $\chi^{2}=5.71, d f=4, p=0.22$ \\
\hline Dose increase $\geq 50[\%]^{\mathrm{b}}$ & 30.0 & 10.5 & 25 & 50 & 33.3 & - & $\chi^{2}=6.87, d f=4, p=0.14$ \\
\hline \multicolumn{8}{|l|}{ Other treatments $[\%]$} \\
\hline SSRI & 11.9 & 10.5 & 11.4 & 7.1 & 2.8 & $31(20)$ & $\chi^{2}=2.54, d f=4, p=0.64$ \\
\hline Other AD & 4.8 & 5.3 & 6.8 & 0 & 2.8 & $31(20)$ & $\chi^{2}=1.49, d f=4, p=0.83$ \\
\hline LIT & 11.9 & 5.3 & 13.6 & 7.1 & 13.9 & $31(20)$ & $\chi^{2}=1.38, d f=4, p=0.85$ \\
\hline Other MS & 21.4 & 10.5 & 13.6 & 7.1 & 8.3 & $31(20)$ & $\chi^{2}=3.7, d f=4, p=0.45$ \\
\hline
\end{tabular}

$A D$ antidepressant, $A P$ antipsychotic, $A R P$ aripiprazole, $C L Z$ clozapine, $C P Z$ eq chlorpromazine equivalents, $d f$ degrees of freedom, $L I T$ lithium, $N M S$ neuroleptic malignant syndrome, $O L A$ olanzapine, $Q U E$ quetiapine, $R S P$ risperidone, SSRI selective serotonin reuptake inhibitor, $M S$ mood stabilizers, $S D$ standard deviation

$* p<0.05$

${ }^{\text {a }}$ Any dose increase of AP in the 5 days preceding NMS onset

${ }^{b}$ Percentage of dose increase was calculated as $100 \%$ when the APs were newly introduced in the 5 days before NMS diagnosis

c Missing values over $25 \%$

Instead, a steep dose titration before NMS was found more frequently in the aripiprazole group than in the quetiapine group (50 vs. $10.5 \% ; p=0.04$ ). Olanzapine, quetiapine, and risperidone were more often associated with antidepressant use than clozapine and aripiprazole. Lithium was prescribed to $5.3 \%$ of participants using quetiapine and up to $13.9 \%$ of those taking clozapine.

\subsubsection{NMS Clinical Features}

The comparisons of the prevalence, duration, and severity of NMS symptoms are reported in Table 3. The clinical presentation of NMS showed significant differences according to the SGA used; rigidity and tremor were less frequent in CLZ-NMS than in other subgroups ( $p<0.01$ and $p=0.03$, respectively). While a degree of hyperpyrexia was almost ubiquitary, higher temperatures were less commonly observed for aripiprazole $(58.3 \%)$ than other SGAs, but this difference did not reach statistical significance $(p=0.10)$. Diaphoresis was constant or very frequent in olanzapine, quetiapine, and clozapine $(100,100$, and $94 \%$, respectively), less frequent in risperidone $(75 \%)$, and in cases of aripiprazole-induced NMS (ARP-NMS) [42.9\%; $p=0.001]$. Considering laboratory tests, both $\mathrm{CK}$ elevation and leukocytosis were very frequent without showing intra-class differences.

Global severity was significantly lower for CLZ-NMS than risperidone-induced NMS (RSP-NMS) $[p=0.02]$ or olanzapine-induced NMS (OLA-NMS) $[p=0.03]$. There was no significant association between global severity and age $(r=0.07, p=0.48)$, gender $(t=1.37, p=0.17)$, diagnoses $(F=0.18, \quad p=0.91), \quad$ antipsychotic dose ( $r=0.08, p=0.44$ ) or percentage of dose increase in the preceding week $(r=0.13, p=0.48)$, use of mood stabilizers $(t=0.49, p=0.69)$ or benzodiazepines $(t=0.76$, $p=0.45)$ in the preceding week. There was a statistical trend for an association between antidepressant use in the past week and a higher global severity (37.0 \pm 9.6 vs. $32.4 \pm 8.7 ; p=0.08$ ) but this disappeared after adjusting for the type of antipsychotic.

There were differences in the timing of the onset of some symptoms between the SGA-NMS subgroups (see Table 5), although no comparison reached statistical 


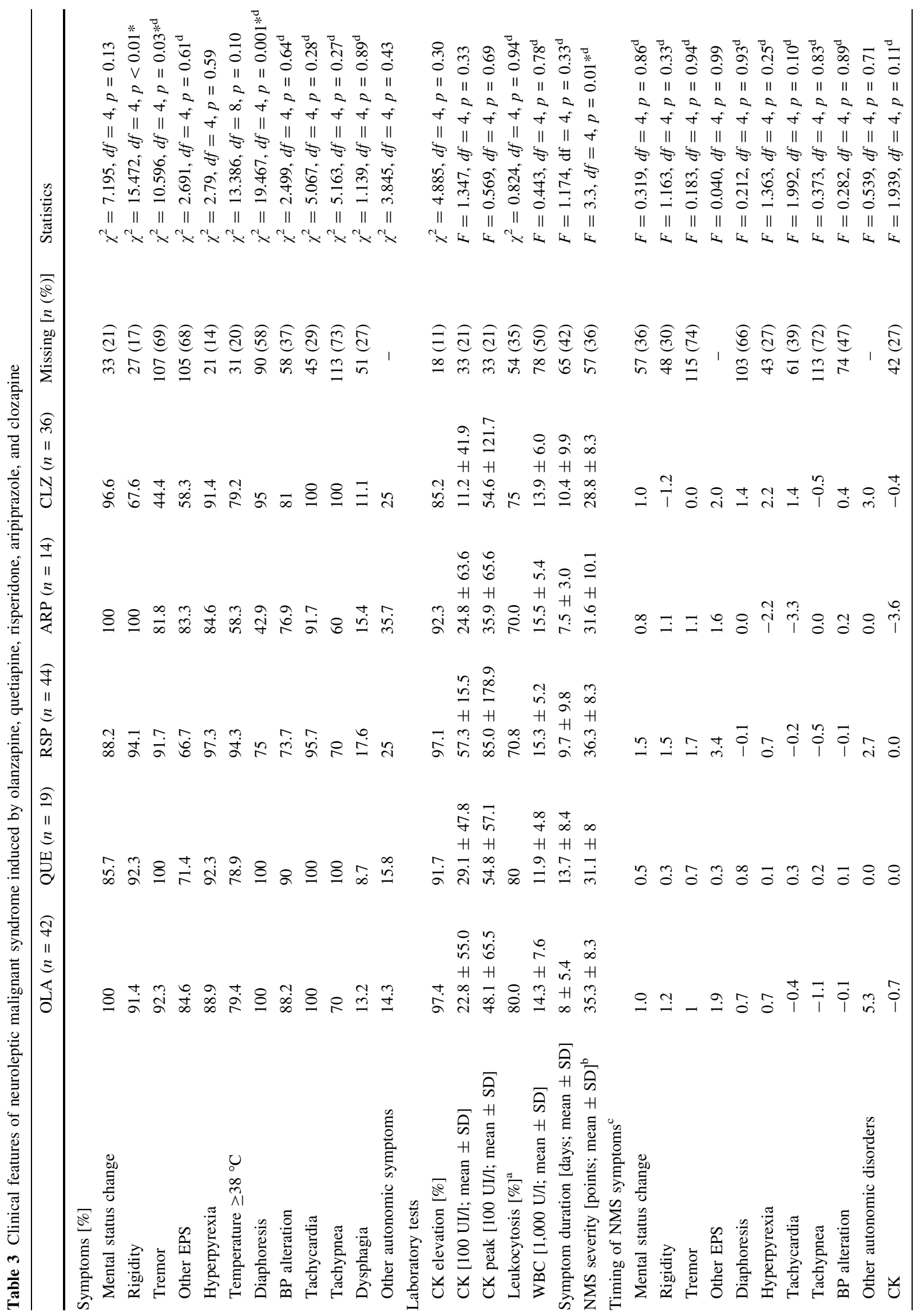


significance. For olanzapine and clozapine, the first symptoms to appear were autonomic disorders (nausea, vomiting, and fecal and urinary incontinence), while for risperidone and aripiprazole, the first symptoms to appear were extrapyramidal symptoms (EPS; akathisia, diskinesia, bradikinesia, myoclonus, hyperreflexia, hyporeflexia). Quetiapine-induced NMS (QUE-NMS) seemed to appear suddenly, showing most symptoms on the same day, with the exception of diaphoresis and tremor. In most cases, rigidity and tremor appeared rapidly, particularly in RSPNMS (mean 1.5 and 1.7 days before NMS diagnosis, respectively), while in CLZ-NMS, hyperpyrexia and tachycardia were early symptoms (2.2 and 1.4 days before NMS diagnosis, respectively). Finally, CK elevation always followed the NMS date, particularly in the aripiprazole subgroup.

\subsubsection{NMS Management and Clinical Outcomes}

Table 4 reports the comparison of clinical management between the subgroups of SGA-NMS. Only one-third of patients required intubation and transfer to the intensive care unit (ICU), with no intraclass differences. Antiparkinsonian drugs were used in approximately half of the cases in the risperidone and aripiprazole subgroups, and in one third of those in the olanzapine and clozapine groups $(p=0.07)$.

Complete recovery was the most frequent outcome, with highest rates in the risperidone groups $(87.9 \%)$ and the lowest in the quetiapine groups $(61.5 \% ; p=0.37)$. Overall, a fatal outcome was reported in less than $10 \%$ of cases-from no reported cases for aripiprazole to $7.1 \%$ for clozapine, and $7.7 \%$ for those receiving quetiapine $(p=0.81)$. Exploratory analyses showed that lethal cases were older in age than non-lethal cases (59.5 \pm 14 vs. $40.0 \pm 20.5 ; t=2.64 ; p=0.009)$, while they did not differ significantly in terms of gender $(p=0.47)$ or previous use of antipsychotic $(p=0.81)$. The dose of antipsychotic in chlorpromazine equivalents was even lower, although not significantly $(295 \pm 209$ vs. $141 \pm 102$; $t=1.63 ; p=0.11)$. Use of mood stabilizers was not associated with death $(p=0.62)$, while the use of an antidepressant in the preceding week showed a more frequent trend in lethal cases than in non-lethal cases (37.5. vs. $\left.12.4 \% ; \chi^{2}=4.00 ; p=0.08\right)$, that persisted after adjusting for age $(p=0.07)$.

\section{Discussion}

The aim of this review was to systematically examine the available evidence on NMS induced by SGAs. Primary studies suggest that SGA-NMS differs from FGA-NMS in 
Table 4 Clinical management of neuroleptic malignant syndrome induced by olanzapine, quetiapine, risperidone, aripiprazole, and clozapine

\begin{tabular}{|c|c|c|c|c|c|c|c|}
\hline & $\begin{array}{l}\text { OLA } \\
(n=42)\end{array}$ & $\begin{array}{l}\text { QUE } \\
(n=19)\end{array}$ & $\begin{array}{l}\text { RSP } \\
(n=44)\end{array}$ & $\begin{array}{l}\text { ARP } \\
(n=14)\end{array}$ & $\begin{array}{l}\text { CLZ } \\
(n=36)\end{array}$ & $\begin{array}{l}\text { Missing } \\
{[n(\%)]}\end{array}$ & Statistics \\
\hline \multicolumn{8}{|l|}{ NMS treatment [\%] } \\
\hline ICU and intubation & 35.7 & 30.0 & 24.2 & 38.5 & 29.2 & 47 (30) & $\chi^{2}=1.38, d f=4, p=0.85^{\mathrm{a}}$ \\
\hline Any antiparkinsonian & 34.4 & 40 & 59.0 & 53.8 & 27.6 & $27(17)$ & $\chi^{2}=8.52, d f=4, p=0.07$ \\
\hline Dopaminergic & 30.3 & 40 & 53.8 & 38.5 & 27.6 & $26(17)$ & $\chi^{2}=6.27, d f=4, p=0.18$ \\
\hline Anticholinergic & 3.1 & 6.7 & 10.3 & 23.1 & 3.4 & 27 (17) & $\chi^{2}=6.30, d f=4, p=0.18$ \\
\hline Myorelaxants & 51.5 & 86.7 & 48.7 & 61.5 & 51.3 & $26(17)$ & $\chi^{2}=7.21, d f=4, p=0.13$ \\
\hline \multicolumn{8}{|l|}{ Outcome $[\%]$} \\
\hline Complete recovery & 75 & 61.5 & 87.9 & 81.8 & 80 & $50(32)$ & $\chi^{2}=4.32, d f=4, p=0.37^{\mathrm{a}}$ \\
\hline Death & 6.5 & 7.7 & 2.9 & 0 & 7.1 & $36(23)$ & $\chi^{2}=1.64, d f=4, p=0.81$ \\
\hline
\end{tabular}

$A R P$ aripiprazole, $C L Z$ clozapine, $d f$ degrees of freedom, $I C U$ intensive care unit, $N M S$ neuroleptic malignant syndrome, $O L A$ olanzapine, $Q U E$ quetiapine, $R S P$ risperidone

${ }^{\text {a }}$ Missing values over $25 \%$

regard to its epidemiology, clinical features, and outcomes. Furthermore, the analysis of case reports of SGA-NMS highlighted the presence of clinical heterogeneity among NMS induced by different SGAs, particularly for clozapine, aripiprazole, and amisulpride.

\subsection{Comparison Between SGA-NMS and First- Generation NMS}

Almost 30 years have elapsed since Pope and colleagues reported the first case of NMS induced by an atypical antipsychotic [5]. Despite this, the knowledge on SGANMS is still quite limited and few studies have been conducted with a systematic methodology. Available evidence suggests that NMS is less frequent during treatment with SGAs than with FGAs. Two studies collected spontaneous reporting from pharmacovigilance databases and estimated an annual incidence of SGA-NMS at $0.056 /(1,000 \times$ year $)$ in patients receiving olanzapine [14] and 0.064/ $(1,000 \times$ year $)$ among patients receiving various SGAs [19], whereas a recent meta-analysis indicated that SMN occurred in 0.17-32 persons for every 1,000 receiving FGAs [13]. However, both figures relative to FGAs and SGAs should be considered only indicative given that epidemiological data on SMN are affected by significant methodological bias. Furthermore, the meta-analysis reporting data on FGA-NMS is more likely to have overestimated its prevalence since it included studies that were mostly conducted on inpatients, among whom NMS tends to occur more frequently. However, in a direct comparison, SGAs were still associated with an almost threefold higher probability of incident NMS than FGAs [22].

A few significant risk factors for SGA-NMS could be identified, i.e. male gender, confusion, dehydration, delirium, and EPS in one study [19], and non-White ethnicity, number of antipsychotics, use of aripiprazole, and increasing/fluctuant dosing patterns in another [22]. This is broadly similar to findings on FGA-NMS, although data are still too limited to draw meaningful comparisons $[28$, 29].

Only one study directly compared the clinical features of SGA-NMS and FGA-NMS, and did not find overall between-class differences. However, it is noteworthy that CLZ-NMS alone was characterized by less rigidity and EPS than other SGAs [11]. Other studies also suggested that SGA-NMS was associated with a less severe clinical picture than FGA-NMS, since the authors found lower rates of admissions to the ICU [20], and lower mortality rates than for FGA-NMS $[11,20]$. In our case review, eight cases of SGA-NMS were lethal, from a total of 145 cases that reported this information $(5.5 \%)$. Therefore, the mortality rate seems to be much lower for SGA-NMS than previous estimates of 10-20\% among cases of FGA-NMS $[30,31]$. Consistent with other reports, in our analysis lethal cases tended to occur in older individuals $[11,31]$.

\subsection{NMS Induced by SGAs}

Newer antipsychotics are commonly grouped under the umbrella term of 'atypical' or 'second-generation' compounds, given their relative freedom from risks of adverse extrapyramidal effects $[4,11]$. However, it was well established that each SGA possesses specific pharmacokinetic and pharmacodynamic properties, as well as different profiles of clinical effects and toxicity $[9,10]$. Pharmacological properties might constitute the basis of intraclass differences in the expression of SGA-NMS.

\subsubsection{Olanzapine}

Cardinal signs of NMS were present in the vast majority of cases of OLA-NMS, while 10-20\% did not display EPS or 
Table 5 Neuroleptic malignant syndrome induced by amisulpride, paliperidone, ziprasidone, and zotepine

\begin{tabular}{|c|c|c|c|c|c|}
\hline & $\mathrm{AMI}(n=7)$ & PAL $(n=4)$ & $\mathrm{ZPR}(n=6)$ & ZOT $(n=4)$ & Missing $[n(\%)]$ \\
\hline Gender, female & 28.6 & 50 & 66.7 & 25 & - \\
\hline Age [years; mean $\pm \mathrm{SD}$ ] & $47.6 \pm 18.9$ & $39.5 \pm 24.7$ & $35 \pm 16.1$ & $52.5 \pm 13.6$ & - \\
\hline Ethnicity [Caucasian; \%] & 33.3 & 100 & - & 40 & $18(60)$ \\
\hline \multicolumn{6}{|l|}{ Diagnosis [\%] } \\
\hline Psychotic disorders & 42.9 & 75 & 66.7 & 100 & \\
\hline Mood disorders & 28.6 & - & 33.3 & - & \\
\hline Dementia & 28.6 & - & - & - & \\
\hline Other & - & 25 & - & - & \\
\hline Mean dose $[\text { mean } \pm \mathrm{SD}]^{\mathrm{a}}$ & $480 \pm 179$ & $7.5 \pm 1.7$ & $86.7 \pm 46.8$ & $325 \pm 247$ & $8(26.7)$ \\
\hline \multicolumn{6}{|l|}{ Symptoms [\%] } \\
\hline Mental status change & 100 & 100 & 100 & 100 & $2(6.7)$ \\
\hline Rigidity & 83.3 & 100 & 80 & 100 & $5(16.7)$ \\
\hline Diaphoresis & 75 & 100 & 100 & 100 & $12(38.7)$ \\
\hline Hyperpyrexia & 71.4 & 100 & 100 & 100 & $3(10)$ \\
\hline Temperature $\geq 38{ }^{\circ} \mathrm{C}$ & 50 & 50 & 50 & 66.7 & $4(13.3)$ \\
\hline Tachycardia & 80 & 100 & 100 & 100 & $10(33.3)$ \\
\hline Tachypnea & - & - & 33 & - & $24(80)$ \\
\hline $\mathrm{BP}$ alteration & 83.3 & 75 & 83.3 & - & $7(23.3)$ \\
\hline Other autonomic symptoms & 100 & 25 & 33.3 & - & - \\
\hline Tremor & - & 100 & 100 & 50 & $17(56.7)$ \\
\hline Other EPS & - & 100 & 100 & - & $23(76.7)$ \\
\hline \multicolumn{6}{|l|}{ Laboratory tests } \\
\hline CK [100 UI/l; mean \pm SD] & $77.9 \pm 62.9$ & $74.2 \pm 129$ & $319 \pm 437$ & $21.3 \pm 37.3$ & - \\
\hline CK peak $[100 \mathrm{UI} / 1 ;$ mean $\pm \mathrm{SD}]$ & $79.5 \pm 61.5$ & $76.7 \pm 128$ & $382 \pm 475$ & $392 \pm 392$ & $3(10)$ \\
\hline Leukocytosis [\%] & 80 & 50 & 80 & 100 & $10(33.3)$ \\
\hline WBC $[1,000 \mathrm{U} / 1 ;$ mean $\pm \mathrm{SD}]$ & $16.6 \pm 4.8$ & 16.2 & $20 \pm 9.4$ & $15.3 \pm 2.9$ & $15(50)$ \\
\hline Symptom duration [days; mean \pm SD] & $10.5 \pm 5.8$ & $14.2 \pm 5.7$ & $10.4 \pm 1.5$ & $15.0 \pm 1.5$ & $12(40)$ \\
\hline \multicolumn{6}{|l|}{ Outcome [\%] } \\
\hline Complete recovery & 80 & 100 & 75 & 100 & $10(33.3)$ \\
\hline Death & 20 & - & - & - & $7(23.3)$ \\
\hline
\end{tabular}

$A M I$ amisulpride, $B P$ blood pressure, $C K$ creatine kinase, $E P S$ extrapyramidal symptoms, $P A L$ paliperidone, $S D$ standard deviation, $W B C$ white blood cells, ZPR ziprasidone, ZOT zotepine

${ }^{\text {a }}$ Mean dose on the day of NMS onset

high fever. On average, symptoms of autonomic imbalances were only slightly more frequent in OLA-NMS than in other SGA-NMS, but were often the first signs to appear (up to 5 days prior to NMS diagnosis), followed by EPS and mental status change, and then diaphoresis and fever. Nausea was rare, consistent with established olanzapine antiemetic properties [32], except when it was administered together with sertraline [33] or valproate [34]. Among the most peculiar clinical cases that were reported, OLA-NMS displayed severe neurological symptoms, such as coma [35], hemiplegia [36], ataxia [37], and seizures [38]. Overall, OLA-NMS was reported to be quite rare [14], but several cases have been described in patients taking psychoactive drugs other than antipsychotics, such as antidepressants or mood stabilizers. In these cases, the resulting clinical picture was often characterized by a higher global severity, and resulted in substantial mortality rates. In general, despite the fact that OLA-NMS might present with a different clinical picture than those of typical FGA-NMS, these findings do not seem sufficient to justify the definition of an atypical presentation, as was also noted by previous authors $[6,39,40]$.

\subsubsection{Quetiapine}

The average age of cases suffering from QUE-NMS was high, although one case was reported in a 4-year-old patient [41]. Clinically, QUE-NMS was characterized by the constant presence of EPS and pronounced autonomic symptoms, such as diaphoresis, tachycardia, tachypnea, 
and blood pressure alterations. In particular, the latter symptoms might be related to its inhibition of noradrenaline reuptake, $\alpha$-adrenergic and histaminergic antagonism, and also to serotonin-related toxicity [10]. Of note, this clinical picture was observed in spite of similar patterns in the prescription of other psychotropic drugs, such as antidepressants or mood stabilizers. Symptoms of QUE-NMS seemed to have their onset synchronously, on average a day before the diagnosis of NMS was made. Furthermore, QUE-NMS had the longest duration among SGA-NMS. Together, these elements suggest that an abrupt onset prompted an early diagnosis of NMS by the reporting clinicians, thus prolonging the observation period. The mean severity index was in the low range, but the observed outcomes were overall poor, despite patients received similar supportive treatments as in other SGA-NMS. This is in apparent contrast with previous case reports [6, 42], but might be explained by the higher age of the subjects, which is a significant predictor of negative outcomes [11, 43]. In addition, symptoms of autonomic dysfunction were given a smaller weight than other dimensions of NMS in the rating of clinical severity [18], and this might have led to a relative underestimation of the severity of QUE-NMS. Overall, the clinical picture of QUE-NMS seems similar to that of OLA-NMS, which is consistent with several commonalities in their pharmacological profiles [10]; this suggests caution in the definition of an 'atypical' presentation.

\subsubsection{Risperidone}

Since publication of the review by Trollor and colleagues [6], ten cases of RSP-NMS have been published. Overall, RSP-NMS was frequently observed among younger patients, more often neuroleptic-naïve, who mostly developed full-blown, severe clinical presentations. Notably, the presentation of RSP-NMS was characterized by marked EPS, high temperatures, and great elevations of the indexes of rhabdomyolysis. Among autonomic signs, tachycardia was more common than diaphoresis (96 vs. $75 \%$ ). On average, most cardinal signs of NMS had already appeared 1-3 days prior to the formal diagnosis of NMS, while the onset of fever was recorded only 0.7 days earlier. It seems likely that fever could have been the sign that led clinicians to perform further laboratory tests, often carried out on the same day of the diagnosis. One-third of cases of RSP-NMS also showed other autonomic gastrointestinal symptoms, such as vomiting, diarrhea, or sialorrhea, which generally appeared early in its course. Furthermore, $17 \%$ of cases of RSP-NMS presented with dysphagia; notably, this symptom has also been described as a dose-dependent, reversible side effect of risperidone, closely related to EPS [44]. After the onset of full-blown NMS, signs of cardiorespiratory dysregulation appeared in most cases. In anecdotal cases, RSP-NMS was even accompanied by acute pancreatitis [45] or dermatologic lesions [46]. RSPNMS was treated promptly with high doses of antiparkinsonian drugs and, despite it being significantly more severe than other SGA-NMS, it often led to complete recovery. Overall, the descriptions provided by available clinical cases are largely compatible with a 'typical' presentation $[42,47]$.

\subsubsection{Aripiprazole}

Since last review on this topic [6], five more cases of ARPNMS have been published, with similar characteristics to those that were already available. Although aripiprazole was given at standard doses, half of the cases of NMS seemed to be triggered by a relatively fast titration scheme. Clinical presentation of ARP-NMS was characterized by the constant presence of rigidity and mental status changes, the highest rates of nausea and vomiting, and by a lower frequency of hyperpyrexia, diaphoresis, and tachypnea than other SGA-NMS. Despite all cases suffering rigidity and frequent EPS of other types, rhabdomyolysis seemed to be associated with lower peaks of CK. All the main symptoms appeared earlier or on the same day of NMS diagnosis, with the exception of hyperpyrexia (mean 2.2 days later than the diagnosis). Fever was also less severe than for other SGA-NMS. The severity and duration of NMS was lower than for other SGA-NMS, possibly related to the peculiar pharmacodynamic profile of aripiprazole. In fact this compound not only exerts partial agonist activity on the $\mathrm{D}_{2}$ receptor but also on the $\mathrm{D}_{3} \mathrm{D}_{4}$ and $5-\mathrm{HT}_{1 \mathrm{~A}}$ receptors [10]. A wide proportion of cases with ARP-NMS were younger in age and were promptly admitted to the ICU, which might be the reason for the absence of mortality. Overall, the clinical picture of ARP-NMS might be considered, at least in part, 'atypical' due to a lower incidence of high fever and diaphoresis.

\subsubsection{Clozapine}

Since the publication of the review by Trollor and colleagues [6], five more reports of CLZ-NMS have been published. Cases of CLZ-NMS were characterized by rapid dose increases, limited concurrent use of antidepressants or mood stabilizers, and high rates of previous treatments with other antipsychotics. Furthermore, patients suffering CLZNMS had a more frequent clinical history of previous NMS. Tachycardia, tachypnea, blood pressure lability, and other autonomic symptoms were very frequent and severe, possibly related to the high affinity of clozapine for adrenergic and muscarinic receptors [48]. Fever was often one of the first symptoms to appear, together with 
autonomic dysfunction, and this clinical picture often made it necessary to rule out clozapine-related agranulocytosis [49]. In fact, increases of CK were lower and delayed [50] and EPS were generally more rare, consistent with the lower affinity of clozapine for $\mathrm{D}_{2}$ receptors [51]. EPS appeared at various stages along the course of CLZ-NMS, often as mild early signs which were followed by tremor and, only after a mean of 1.2 days from the diagnosis of NMS, rigidity. Overall, the duration of CLZ-NMS was longer than other SGA-NMS but was associated with lower clinical severity. Consistently, cases of CLZ-NMS received, less frequently, antiparkinsonian agents and admission to the ICU; high mortality rates could have derived from possible underestimation of its severity. The rarity of EPS in the context of CLZ-NMS has been previously noted [11, 52, 53], and underlines the need for taking NMS in consideration even when a full-blown clinical picture is absent. On the other side, some authors have argued that some of these cases would fall outside the boundaries of stringent diagnostic classifications, therefore they should not diagnosed as NMS in the first place [53]. However, there is little doubt that the presentation of CLZNMS can be considered as the most atypical among SGANMS [6, 11].

\subsubsection{Amisulpride}

Despite several decades of amisulpride use, only seven cases of amisulpride-induced NMS (AMI-NMS) have been described [8, 54-59]. Most cases occurred in older males. Among the cases of AMI-NMS, four occurred following an increase in the dose of the drug, and one led to the death of the patient. The clinical picture was characterized by the constant presence of mental status alterations, frequent rigidity (83\%), and high levels of CK. Instead, high fever, other EPS, and other autonomic symptoms were less frequently reported than in other SGA-NMS. Based on these findings some authors, but not all [11], have advocated for an 'atypical' presentation of AMI-NMS [57, 58]. Furthermore, similar to CLZ-NMS, the duration of symptoms appeared to be slightly longer than for other SGA-NMS; this could reflect the fact that patients received less prompt or intensive clinical management. Considering its pharmacologic properties, amisulpride has a peculiar mechanism of action that relies on a delayed pattern of $D_{2} / D_{3}$ receptor occupancy, involving also presynaptic mechanisms with an apparent specificity for mesolimbic pathways. These features are thought to be related to its low capacity to induce EPS, and might also explain the low occurrence of NMS with this drug [60]. Furthermore, amisulpride has a low affinity for muscarinic, $\alpha$-adrenergic, serotonergic, and histamine receptors, which could explain the lower induction of autonomic dysfunction [61].

\subsubsection{Paliperidone}

PAL is the main active metabolite of RSP and has a similar receptor profile, being a $D_{2}$ receptor antagonist-although with lower affinity than RSP- and a 5- $\mathrm{HT}_{2 \mathrm{~A}}$ antagonist [62]. Only four cases of NMS were induced by paliperidone [63-66], three of which emerged in patients suffering from schizophrenia, and appeared when subjects were treated at doses of 6-9 mg. Most cases had been previously treated with other SGAs, with recent cross-titration schemes or dose increases. Paliperidone-induced NMS (PAL-NMS) was characterized by a typical presentation, with nearly all cases presenting with mental status alteration, rigidity, diaphoresis, hyperpyrexia (even if only half of the cases reached a temperature higher than $38^{\circ} \mathrm{C}$ ), tremor, and other EPS. All cases had a favorable evolution, with complete recovery of patients.

\subsubsection{Ziprasidone}

Six cases of ziprasidone-induced NMS (ZPR-NMS) were included [67-72], whereas a previous review examined five cases [6]. The mean age of patients was 35 years; twothirds of patients were females and the same proportion was diagnosed with a psychotic disorder. The onset of NMS was generally abrupt, with most cases displaying typical symptoms such as alterations of mental status, diaphoresis, hyperpyrexia, tachycardia, blood pressure alterations, leukocytosis, tremor, and other EPS. Levels of CK were very high and became evident soon after the onset of the syndrome; however, only half of the cases reached a temperature higher than $38^{\circ} \mathrm{C}$. Notably, in two cases rigidity was absent $[67,72]$, while in one case it superimposed on pre-existing Parkinson's disease [68]. Hence, the effective presence of rigidity might be lower for ZPRNMS than for other SGA-NMS, consistent with a lower affinity for D2 receptors [73]. The overall outcome of ZPRNMS was generally favorable; no case was lethal and most patients underwent complete recovery within 10 days of diagnosis.

\subsubsection{Zotepine}

Zotepine is an atypical antipsychotic antagonizing seroto$\operatorname{nin}\left(5-\mathrm{HT}_{2 \mathrm{~A}}, 5-\mathrm{HT}_{2 \mathrm{C}}, 5-\mathrm{HT}_{6}\right.$, and $\left.5-\mathrm{HT}_{7}\right)$ and dopamine $\left(\mathrm{D}_{1}\right.$ and $\mathrm{D}_{2}$ ) receptor. Furthermore, it also has noradrenaline reuptake inhibition properties [74]. Four cases of ZOTNMS were found [75-78]. Only one case occurred in a woman, and the mean age of patients was higher than among other cases of SGA-NMS (52.5 years). Rapid dose escalation was reported in only one case prior to zotepineinduced NMS (ZOT-NMS) onset, but the mean dose was in the high range $(325 \mathrm{mg})$. ZOT-NMS was characterized by 
most cardinal symptoms and by a slightly longer duration than other SGA-NMS (15 days). All cases were reported to present with alterations of mental status, rigidity, diaphoresis, hyperpyrexia, tachycardia, and leukocytosis. However, a lower proportion displayed high fever, tremor, tachypnea, alterations in pressure or other symptoms of autonomic imbalance. On average, mean CK values showed a large increase in the days following NMS diagnosis (from 2,130 to a peak value of 39,190 UI/l), similar to what was observed in CLZ-NMS. All cases underwent complete recovery.

\subsection{Diagnostic Issues}

Considering the case reports of SGA-NMS that were reviewed, it is surprising that very few authors stated which set of diagnostic criteria they relied on. In the past years more than 12 sets of criteria were proposed to operationalize NMS, each characterized by different type, number of symptoms, and by differences in the weight they are given to establish the diagnosis [1, 79]. There is still ongoing debate regarding which clinical features should be used to diagnose NMS; disagreement between diagnostic criteria appears to be high, and most criteria sets do not correspond to the empirical diagnoses that are adopted in clinical practice [80].

In our review, the DSM-IV-TR criteria were the most frequently used and could be considered as fairly stringent; they require the presence of both elevated temperature (without defining a specific threshold) and severe muscle rigidity, plus two other minor criteria such as autonomic disorders, other EPS, mental status changes, and laboratory alterations [23]. The criteria set by Adityanjee and Aderibigbe are among the most stringent, and require both fever over $39^{\circ} \mathrm{C}$ and rigidity as necessary conditions to diagnose NMS; by admission of the authors themselves, several cases of SGA-NMS would not reach the diagnostic threshold [79].

On the contrary, Levenson proposed that NMS could be diagnosed even in the absence of rigidity, if CK alterations were observed [24]. This would allow an easier inclusion of atypical forms, although the diagnostic boundaries of NMS would lose specificity [16, 42]. Similarly, other criteria set allow the possibility of diagnosing probable, as opposed to definite, cases of NMS by including those cases without cardinal signs, such as rigidity or fever [26, 81]. Several authors have in fact advocated for the adoption of a spectrum-conceptualization of NMS (i.e. using a dimensional model rather than a dichotomous approach), which might help in clarifying the pathogenetic mechanisms of this syndrome [16]. Indeed, it was argued that the rise of clinical awareness towards NMS and the more widespread availability of treatments makes the natural course of the syndrome more likely to be influenced by early treatments and/or antipsychotic discontinuation, possibly leading to frequent observations of prodromal or abortive stages $[6$, $16,82]$. On a similar note, other authors proposed to add diagnostic specifiers for the clinical stage of NMS [83, 84].

More recently, a new set of criteria was developed and validated by a panel of experts using a Delphi consensus method [1, 85], and was incorporated into the DSM-5 [86]. Interestingly, these criteria do not imply the need for a specific number of 'major' or 'minor' symptoms, but provide specific quantitative criteria for the severity of symptoms, with a pre-defined threshold score used to define the 'caseness' of NMS. This approach might be more suitable to inform future research on NMS, taking into account the existing clinical variants.

\subsection{Pathogenesis}

NMS can be described as a complex cascade of dysregulation in multiple neurochemical and neuroendocrine systems, potentially culminating in an end-stage hypermetabolic syndrome [84]. It has been generally regarded as an idiosyncratic drug reaction, implying that it is unpredictable and dose-independent, although this view has been recently challenged in consideration of cases of NMS induced by antipsychotic withdrawal [15, 17]. However, individual vulnerability for the development of NMS might exist, related to variations in the genes for neurotransmitter receptors or metabolic activity, although evidence in this regard is still preliminary [87, 88].

The exact pathogenetic mechanism that underlies NMS is still partly unknown. The fundamental triggering element seems to be a reduction in CNS dopaminergic tone, along with the dysregulation of autonomic nervous system activity, characterized by a loss of hierarchical integration and control. The functional imbalances seen during NMS are maintained by different feed-forward cycles that involve an increasing number of systems, leading to progressive damage of the muscular tissue and multi-organ failure $[84,89]$. The hypothesis of hypodopaminergic tone was mainly based on the notion that the risk of developing NMS seemed to parallel the ability of the antipsychotic to induce EPS and the degree of inhibition of dopamine receptor activity, particularly the $\mathrm{D}_{2}$ subtype in the nigrostriatal pathways [16, 84]. Reductions in the dopaminergic tone are also deemed responsible for the abrupt shifts that occur in the activity of the hypothalamic thermoregulatory system, which would in turn induce further dysregulation of the autonomic response [4, 84]. However, the report of NMS induced by withdrawal of antipsychotic [15] or induced by the use of SGAs such as clozapine, aripiprazole and amisulpride have cast doubt on the primary role of $\mathrm{D}_{2}$ receptors, at least on the notion that $\mathrm{D}_{2}$ receptors play a predominant role in all cases of NMS [16, 53, 89]. In fact, 
these SGAs possess only weak activity at this level, with aripiprazole even acting as a partial agonist [10]. Not coincidentally, our case review showed that the same SGAs are associated with the highest rates of NMS with atypical features, i.e. lacking severe EPS/rigidity, high fever, or grossly elevated CK. Thus, it is now widely acknowledged, although awaiting further confirmation, that receptors other than dopaminergic (i.e. serotonergic, adrenergic, and cholinergic) might play an important role in the pathophysiology of NMS since they are known to take substantial part in extrapyramidal motor functions [90], thermoregulation, muscle metabolism [89], and mental status [16].

The serotonergic receptors, in particular, have gained increasing attention in recent years as possible contributors to the pathophysiology of NMS, especially that induced by SGAs. In part, this hypotheses spawned from the observation that important similarities exist between NMS and serotonin syndrome at the clinical level. According to this line of research, serotonin-related toxicity would be responsible for the pathogenesis of at least some symptoms of NMS, and this would be particularly evident among atypical SGA-NMS [91-93]. In apparent contrast with this hypothesis, most SGAs antagonize $5-\mathrm{HT}_{2 \mathrm{~A}}$ receptors, and were even suggested for use in the treatment of serotonin syndrome. However, it is noteworthy that quetiapine, aripiprazole, clozapine, and ziprasidone share agonistic actions at $5-\mathrm{HT}_{1 \mathrm{~A}}$ receptors; their stimulation was thus proposed to contribute to lower degrees of hyperthermia or EPS that are observed in some cases of SGA-NMS [16, 90]. Moreover, it was recently hypothesized that long-term treatment with SGAs might determine unbalances in serotonergic neurotransmission, leading to sensitization towards SGAs and other psychotropic agents [94, 95]. Lastly, the observation of cases of NMS apparently precipitated by antidepressants, lithium, or other mood stabilizers have further highlighted a possible pathogenetic role for serotonin, although these drugs are unlikely to trigger NMS alone, in the absence of previous antipsychotic use. However, it was postulated that an excess of central serotonin due to antidepressant use could determine a 'relative hypodopaminergic state', which might increase the risk of developing NMS [96, 97]. In our case review, only statistical trends were found for an association between antidepressants and worse clinical picture of NMS, and further studies based on larger samples are warranted before any clear role of these drugs can be confirmed. Overall, further evidence is also needed to elucidate the role of serotonergic neurotransmission in the pathophysiology of NMS.

\subsection{Limitations}

Our review needs to be evaluated in the light of its limitations, particularly related to the case review.
A dataset based on published case reports is only partially representative of the clinical reality because of its intrinsic nature. It can be affected by reporting biases related both to the reporting clinicians (e.g. authors might have tended to more frequently report cases of NMS with more peculiar presentations; some symptoms could be omitted from the report because they were not considered to depend on NMS, and in some cases serotonin syndrome might have been misdiagnosed for NMS) and to peer reviewers (e.g. possible lower acceptance rates for cases of SGA-NMS for which a wider literature already exists). However, since SGA-NMS is a rare condition, case reports are, by necessity, one of the few available sources of information.

We also included those cases where the authors did not report validating the diagnosis against standardized criteria; it is possible that if such criteria were applied, some cases would not have reached a formal diagnosis of NMS, possibly because patients received early treatment and underwent a partial resolution of symptoms [15]. Hence, the interpretation of findings needs to take into account a possible overrepresentation of atypical cases. However, it needs to be considered that, even when standardized criteria for NMS are used, agreement between different sets is still limited $[15,80]$, while the process of peer review of reports might contribute to filter out the more ambiguous cases [6]. Lastly, this inclusive approach is in line with the conceptualization of NMS as a spectrum proposed by several authors $[16,80]$.

The method for the extraction and coding of data was designed to be as conservative as possible, e.g. abstaining from labeling as absent those symptoms that were not mentioned in the reports. Nonetheless, this method might have introduced bias in the frequency of some symptoms, particularly towards overestimation. However, data on missing values were provided to aid in the interpretation of results.

Given the subgroup size, the statistical power was inadequate to detect some meaningful differences; therefore, statistical analyses should be considered only as exploratory and hypothesis generating.

\section{Conclusions and Directions for Future Research}

Clinicians should be aware that NMS is virtually associated with all antipsychotics, including the most recently marketed antipsychotics. SGA-NMS seems characterized by lower incidence, lower clinical severity, and more rare lethal outcomes than FGA-NMS. The clinical presentation of NMS induced by olanzapine, risperidone, quetiapine, paliperidone, and ziprasidone seems to be widely similar to that of 'typical' NMS, whereas 'atypical' presentations 
might be observed more frequently during NMS triggered by clozapine (less severe EPS), aripiprazole (less severe fever and autonomic symptoms), and amisulpride (less severe EPS and fever). The clinician should pay particular attention to cases developing in older individuals and those receiving antidepressant drugs as these factors might increase the risk of mortality.

Further research is greatly needed to increase our knowledge on NMS and its pathophysiology in order to inform the clinical management of this severe condition. In particular, since case reports or pharmacovigilance systems are the main current sources of information, it would be desirable to develop standardized and systematic reporting methods to include detailed, relevant information on the course and severity of symptoms. Research would also likely benefit from the adoption of a spectrum conceptualization of NMS, with heightened vigilance on symptoms of autonomic dysregulation and serotonin toxicity. Moreover, further studies are needed to understand the role of individual liability for NMS (both genetic and related to individual features, such as physical comorbidities), the role of concomitant use of antidepressants, and other psychotropic medication. The recent development of novel, validated diagnostic criteria seems a promising step in this direction [1].

Acknowledgments This study did not require funding. All authors declare they have no conflicts of interest that are directiy relevant to the content of this review.

Open Access This article is distributed under the terms of the Creative Commons Attribution Noncommercial License which permits any noncommercial use, distribution, and reproduction in any medium, provided the original author(s) and the source are credited.

\section{References}

1. Gurrera RJ, Caroff SN, Cohen A, et al. An international consensus study of neuroleptic malignant syndrome diagnostic criteria using the Delphi method. J Clin Psychiatry. 2011;72:1222-8.

2. Shalev A, Hermesh H, Munitz H. Mortality from neuroleptic malignant syndrome. J Clin Psychiatry. 1989;50:18-25.

3. Adityanjee, Sajatovic M, Munshi KR. Neuropsychiatric sequelae of neuroleptic malignant syndrome. Clin Neuropharmacol. 2005;28:197-204.

4. Tarsy D, Baldessarini RJ, Tarazi FI. Effects of newer antipsychotics on extrapyramidal function. CNS Drugs. 2002;16:23-45.

5. Pope HG Jr, Cole JO, Choras PT, et al. Apparent neuroleptic malignant syndrome with clozapine and lithium. J Nerv Ment Dis. 1986;174:493-5.

6. Trollor JN, Chen X, Sachdev PS. Neuroleptic malignant syndrome associated with atypical antipsychotic drugs. CNS Drugs. 2009;23:477-92.

7. Chakraborty N, Johnston T. Aripiprazole and neuroleptic malignant syndrome. Int Clin Psychopharmacol. 2004;19:351-3.
8. Abay E, Kose R. Amisulpride-induced neuroleptic malignant syndrome. J Neuropsychiatry Clin Neurosci. 2007;19:488-9.

9. Grunder G, Hippius H, Carlsson A. The 'atypicality' of antipsychotics: a concept re-examined and re-defined. Nat Rev Drug Discov. 2009;8:197-202.

10. Horacek J, Bubenikova-Valesova V, Kopecek M, et al. Mechanism of action of atypical antipsychotic drugs and the neurobiology of schizophrenia. CNS Drugs. 2006;20:389-409.

11. Trollor JN, Chen X, Chitty K, et al. Comparison of neuroleptic malignant syndrome induced by first- and second-generation antipsychotics. Br J Psychiatry. 2012;201:52-6.

12. Verdoux H, Tournier M, Begaud B. Antipsychotic prescribing trends: a review of pharmaco-epidemiological studies. Acta Psychiatr Scand. 2010;121:4-10.

13. Gurrera RJ, Simpson JC, Tsuang MT. Meta-analytic evidence of systematic bias in estimates of neuroleptic malignant syndrome incidence. Compr Psychiatry. 2007;48:205-11.

14. Biswasl PN, Wilton LV, Pearcel GL, et al. The pharmacovigilance of olanzapine: results of a post-marketing surveillance study on 8858 patients in England. J Psychopharmacol. 2001;15:265-71.

15. Margetić B, Aukst-Margetić B. Neuroleptic malignant syndrome and its controversies. Pharmacoepidemiol Drug Saf. 2010;19:429-35.

16. Odagaki Y. Atypical neuroleptic malignant syndrome or serotonin toxicity associated with atypical antipsychotics? Curr Drug Saf. 2009;4:84-93.

17. Amore M, Zazzeri N. Neuroleptic malignant syndrome after neuroleptic discontinuation. Prog Neuropsychopharmacol Biol Psychiatry. 1995;19:1323-34.

18. Yacoub A, Francis A. Neuroleptic malignant syndrome induced by atypical neuroleptics and responsive to lorazepam. Neuropsychiatr Dis Treat. 2006;2:235-40.

19. Chen Y, Guo JJ, Steinbuch M, et al. Risk of neuroleptic malignant syndrome in patients with bipolar disorder: a retrospective, population-based case-control study. Int $\mathrm{J}$ Psychiatry Med. 2009;39:439-50.

20. Nakamura M, Yasunaga H, Miyata H, et al. Mortality of neuroleptic malignant syndrome induced by typical and atypical antipsychotic drugs: a propensity-matched analysis from the Japanese Diagnosis Procedure Combination database. J Clin Psychiatry. 2012;73:427-30.

21. Nielsen RE, Wallenstein Jensen SO, Nielsen J. Neuroleptic malignant syndrome: an 11-year longitudinal case-control study. Can J Psychiatry. 2012;57:512-8.

22. Su YP, Chang CK, Hayes RD, et al. Retrospective chart review on exposure to psychotropic medications associated with neuroleptic malignant syndrome. Acta Psychiatr Scand. 2014;130:52-60.

23. American Psychiatric Association. Diagnostic and statistical manual of mental disorders. 4th edn, text revision. Washington, DC: American Psychiatric Association; 2000.

24. Levenson JL. Neuroleptic malignant syndrome. Am J Psychiatry. 1985;142:1137-45.

25. Sachdev PS. A rating scale for neuroleptic malignant syndrome. Psychiatry Res. 2005;135:249-56.

26. Pope HG Jr, Keck PE Jr, McElroy SL. Frequency and presentation of neuroleptic malignant syndrome in a large psychiatric hospital. Am J Psychiatry. 1986;143:1227-33.

27. Caroff SN, Mann SC. Neuroleptic malignant syndrome. Med Clin North Am. 1993;77:185-202.

28. Berardi D, Dell'Atti M, Amore M, et al. Clinical risk factors for neuroleptic malignant syndrome. Hum Psychopharmacol. 2002;17:99-102.

29. Berardi D, Amore M, Keck PE Jr, et al. Clinical and pharmacologic risk factors for neuroleptic malignant syndrome: a casecontrol study. Biol Psychiatry. 1998;44:748-54. 
30. Shalev A, Munitz H. The neuroleptic malignant syndrome: agent and host interaction. Acta Psychiatr Scand. 1986;73:337-47.

31. Caroff SN, Campbell EC, Sullivan KA. Neuroleptic malignant syndrome in elderly patients. Expert Rev Neurother. 2007;7:423-31.

32. Licup N. Olanzapine for nausea and vomiting. Am J Hosp Palliat Care. 2010;27:432-4.

33. Arnaout MS, Antun FP, Ashkar K. Neuroleptic malignant syndrome with olanzapine associated with severe hypernatremia. Hum Psychopharmacol. 2001;16:279-81.

34. Filice GA, McDougall BC, Ercan-Fang N, et al. Neuroleptic malignant syndrome associated with olanzapine. Ann Pharmacother. 1998;32:1158-9.

35. Sierra-Biddle D, Herran A, Diez-Aja S, et al. Neuropletic malignant syndrome and olanzapine. J Clin Psychopharmacol. 2000;20:704-5.

36. Stanfield SC, Privette T. Neuroleptic malignant syndrome associated with olanzapine therapy: a case report. J Emerg Med. 2000;19:355-7.

37. Johnson V, Bruxner G. Neuroleptic malignant syndrome associated with olanzapine. Aust NZ J Psychiatry. 1998;32:884-6.

38. Verma R, Junewar V, Rathaur BP. An atypical case of neuroleptic malignant syndrome precipitated by valproate. BMJ Case Rep. 2014;2014. doi:10.1136/bcr-2013-202578.

39. Mishra B, Mishra B, Sahoo S, et al. Atypicality in presentation of neuroleptic malignant syndrome caused by olanzapine. Indian $\mathbf{J}$ Med Sci. 2007;61:570-3.

40. Nielsen J, Bruhn AM. Atypical neuroleptic malignant syndrome caused by olanzapine. Acta Psychiatr Scand. 2005;112:238-40.

41. Randolph TC. Possible contribution of XYY syndrome to neuroleptic malignant syndrome in a child receiving quetiapine. Am J Health Syst Pharm. 2010;67:459-61.

42. Farver DK. Neuroleptic malignant syndrome induced by atypical antipsychotics. Expert Opin Drug Saf. 2003;2:21-35.

43. Bakken GV, Rudberg I, Molden E, et al. Pharmacokinetic variability of quetiapine and the active metabolite $N$-desalkylquetiapine in psychiatric patients. Ther Drug Monit. 2011;33:222-6.

44. Sico JJ, Patwa H. Risperidone-induced bulbar palsy-like syndrome. Dysphagia. 2011;26:340-3.

45. Ghio L, Fornaro G, Rossi P. Risperidone-induced hyperamylasemia, hyperlipasemia, and neuroleptic malignant syndrome: a case report. J Clin Psychopharmacol. 2009;29:391-2.

46. Sugden SG, Bourgeois JA, Kile SJ, et al. Neuroleptic malignant syndrome with dermatologic complications. J Clin Psychopharmacol. 2004;24:676-8.

47. Ananth J, Parameswaran S, Gunatilake S, et al. Neuroleptic malignant syndrome and atypical antipsychotic drugs. J Clin Psychiatry. 2004;65:464-70.

48. Jann MW, Grimsley SR, Gray EC, et al. Pharmacokinetics and pharmacodynamics of clozapine. Clin Pharmacokinet. 1993;24:161-76.

49. Amore M, Zazzeri N, Berardi D. Atypical neuroleptic malignant syndrome associated with clozapine treatment. Neuropsychobiology. 1997;35:197-9.

50. Gambassi G, Capurso S, Tarsitani P, et al. Fatal neuroleptic malignant syndrome in a previously long-term user of clozapine following its reintroduction in combination with paroxetine. Aging Clin Exp Res. 2006;18:266-70.

51. Gerlach J, Lublin H, Peacock L. Extrapyramidal symptoms during long-term treatment with antipsychotics: special focus on clozapine and D1 and D2 dopamine antagonists. Neuropsychopharmacology. 1996;14:35S-9S.

52. Sachdev P, Kruk J, Kneebone M, et al. Clozapine-induced neuroleptic malignant syndrome: review and report of new cases. J Clin Psychopharmacol. 1995;15:365-71.

53. Karagianis JL, Phillips LC, Hogan KP, et al. Clozapine-associated neuroleptic malignant syndrome: two new cases and a review of the literature. Ann Pharmacother. 1999;33:623-30.
54. Gallarda T, Olie JP. Neuroleptic malignant syndrome in an 72-year-old-man with Alzheimer's disease: a case report and review of the literature. Eur Neuropsychopharmacol. 2000;10(Suppl 3):357.

55. Angelopoulos P, Markopoulou M, Kyamidis K, et al. Neuroleptic malignant syndrome without fever after addition of oxcarbazepine to long-term treatment with amisulpride. Gen Hosp Psychiatry. 2008;30:482-4.

56. Ball $\mathrm{H}$, de Waal $\mathrm{H}$, Craig K. An unrecognised case of withdrawal neuroleptic malignant syndrome: a case report. Med Sci Law. 2009;49:298-300.

57. Atbasoglu EC, Ozguven HD, Can SM, et al. Rhabdomyolysis and coma associated with amisulpride: a probable atypical presentation of neuroleptic malignant syndrome. J Clin Psychiatry. 2004;65:1724-5.

58. Tu MC, Hsiao CC. Amisulpride and neuroleptic malignant syndrome. Chang Gung Med J. 2011;34:536-40.

59. Peritogiannis V, Tsouli S, Pappas D, et al. Neuroleptic malignant syndrome due to amisulpride in a patient with solvent-induced chronic toxic encephalopathy. Clin Neuropharmacol. 2007;30:245-6.

60. Perrault G, Depoortere R, Morel E, et al. Psychopharmacological profile of amisulpride: an antipsychotic drug with presynaptic D2/ D3 dopamine receptor antagonist activity and limbic selectivity. J Pharmacol Exp Ther. 1997;280:73-82.

61. Natesan S, Reckless GE, Barlow KB, et al. Amisulpride the 'atypical' atypical antipsychotic: comparison to haloperidol, risperidone and clozapine. Schizophr Res. 2008;105:224-35.

62. de Leon J, Wynn G, Sandson NB. The pharmacokinetics of paliperidone versus risperidone. Psychosomatics. 2010;51:80-8.

63. Duggal HS. Possible neuroleptic malignant syndrome associated with paliperidone. J Neuropsychiatry Clin Neurosci. 2007;19:477-8.

64. Mantas C, Kalabokis G, Goulia P, et al. Possible neuroleptic malignant syndrome during paliperidone administration: a case report. J Clin Psychopharmacol. 2010;30:89-91.

65. Han C, Lee SJ, Pae CU. Paliperidone-associated atypical neuroleptic malignant syndrome: a case report. Prog Neuropsychopharmacol Biol Psychiatry. 2011;35:650-1.

66. Nayak RB, Bhogale GS, Patil NM, et al. Paliperidone-induced neuroleptic malignant syndrome. J Neuropsychiatry Clin Neurosci. 2011;23:E14-5.

67. Borovicka MC, Bond LC, Gaughan KM. Ziprasidone- and lithium-induced neuroleptic malignant syndrome. Ann Pharmacother. 2006;40:139-42.

68. Gray NS. Ziprasidone-related neuroleptic malignant syndrome in a patient with Parkinson's disease: a diagnostic challenge. Hum Psychopharmacol. 2004;19:205-7.

69. Leibold J, Patel V, Hasan RA. Neuroleptic malignant syndrome associated with ziprasidone in an adolescent. Clin Ther. 2004;26:1105-8.

70. Lewis AL, Pelic C, Kahn DA. Malignant catatonia in a patient with bipolar disorder, B12 deficiency, and neuroleptic malignant syndrome: one cause or three? J Psychiatr Pract. 2009;15:415-22.

71. Ozen ME, Yumru M, Savas HA, et al. Neuroleptic malignant syndrome induced by ziprasidone on the second day of treatment. World J Biol Psychiatry. 2007;8:42-4.

72. Murty RG, Mistry SG, Chacko RC. Neuroleptic malignant syndrome with ziprasidone. J Clin Psychopharmacol. 2002;22:624-6.

73. Stahl SM, Shayegan DK. The psychopharmacology of ziprasidone: receptor-binding properties and real-world psychiatric practice. J Clin Psychiatry. 2003;64(Suppl 19):6-12.

74. Green B. Zotepine: a clinical review. Expert Opin Drug Metab Toxicol. 2009;5:181-6.

75. Hsu WC, Lin ST, Chen CC, et al. A self-limiting case of atypical neuroleptic malignant syndrome associated with zotepine. J Clin Psychopharmacol. 2011;31:667-9. 
76. Tsai JH, Yang P, Yen JY, et al. Zotepine-induced catatonia as a precursor in the progression to neuroleptic malignant syndrome. Pharmacotherapy. 2005;25:1156-9.

77. Mieno S, Asada K, Horimoto H, et al. Neuroleptic malignant syndrome following cardiac surgery: successful treatment with dantrolene. Eur J Cardiothorac Surg. 2003;24:458-60.

78. Kato D, Kawanishi C, Kishida I, et al. Effects of CYP2D6 polymorphisms on neuroleptic malignant syndrome. Eur J Clin Pharmacol. 2007;63:991-6.

79. Adityanjee TM, Aderibigbe YA. Proposed research diagnostic criteria for neuroleptic malignant syndrome. Int J Neuropsychopharmacol. 1999;2:129-44.

80. Chang CK, Harrison S, Lee W, et al. Ascertaining instances of neuroleptic malignant syndrome in a secondary mental healthcare electronic medical records database: the SLAM BRC Case Register. Ther Adv Psychopharmacol. 2012;2:75-83.

81. Friedman JH, Davis R, Wagner RL. Neuroleptic malignant syndrome. The results of a 6-month prospective study of incidence in a state psychiatric hospital. Clin Neuropharmacol. 1988;11:373-7.

82. Velamoor VR, Norman RM, Caroff SN, et al. Progression of symptoms in neuroleptic malignant syndrome. J Nerv Ment Dis. 1994;182:168-73.

83. Woodbury MM, Woodbury MA. Neuroleptic-induced catatonia as a stage in the progression toward neuroleptic malignant syndrome. J Am Acad Child Adolesc Psychiatry. 1992;31:1161-4.

84. Strawn JR, Keck PE Jr, Caroff SN. Neuroleptic malignant syndrome. Am J Psychiatry. 2007;164:870-6.

85. Gurrera RJ, Velamoor V, Cernovsky ZZ. A validation study of the international consensus diagnostic criteria for neuroleptic malignant syndrome. J Clin Psychopharmacol. (Epub 22 Aug 2013).

86. American Psychiatric Association. Diagnostic and statistical manual of mental disorders. 5th ed. Arlington (VA): American Psychiatric Association; 2013.
87. Ochi S, Kawasoe K, Abe M, et al. A case study: neuroleptic malignant syndrome with risperidone and CYP2D6 gene variation. Gen Hosp Psychiatry. 2011;33:640-2.

88. Ananth J, Johnson KM, Levander EM, et al. Diabetic ketoacidosis, neuroleptic malignant syndrome, and myocardial infarction in a patient taking risperidone and lithium carbonate. J Clin Psychiatry. 2004;65:724.

89. Gurrera RJ. Sympathoadrenal hyperactivity and the etiology of neuroleptic malignant syndrome. Am J Psychiatry. 1999;156:169-80.

90. Ohno Y, Shimizu S, Tokudome K. Pathophysiological roles of serotonergic system in regulating extrapyramidal motor functions. Biol Pharm Bull. 2013;36:1396-400.

91. Steele D, Keltner NL, McGuiness TM. Are neuroleptic malignant syndrome and serotonin syndrome the same syndrome? Perspect Psychiatr Care. 2011;47:58-62.

92. Perry PJ, Wilborn CA. Serotonin syndrome vs neuroleptic malignant syndrome: a contrast of causes, diagnoses, and management. Ann Clin Psychiatry. 2012;24:155-62.

93. Sokoro AA, Zivot J, Ariano RE. Neuroleptic malignant syndrome versus serotonin syndrome: the search for a diagnostic tool. Ann Pharmacother. 2011;45:e50.

94. Monte AA, Waksman JC. Chronic olanzapine, serotonin receptors, and subsequent serotonin toxicity. J Clin Psychopharmacol. 2010;30:628-9.

95. Marlowe K, Schirgel D. Quetiapine and citalopram: aetiological significances in serotonin syndrome. NZ Med J. 2006;119:U2058.

96. Assion HJ, Heinemann F, Laux G. Neuroleptic malignant syndrome under treatment with antidepressants? A critical review. Eur Arch Psychiatry Clin Neurosci. 1998;248:231-9.

97. Uguz F, Sonmez EO. Neuroleptic malignant syndrome following combination of sertraline and paroxetine: a case report. Gen Hosp Psychiatry. 2013;35:327. 